\title{
How Do Hindfoot Fusions Affect Ankle Biomechanics: A Cadaver Model
}

\author{
Ian D. Hutchinson MD, Josh R. Baxter PhD, Susannah Gilbert MS, \\ MaCalus V. Hogan MD, Jeff Ling FRCAS, Stuart M. Saunders MD, \\ Hongsheng Wang PhD, John G. Kennedy MD
}

Received: 20 July 2015/ Accepted: 4 December 2015/Published online: 21 December 2015

(C) The Association of Bone and Joint Surgeons \& 2015

\begin{abstract}
Background While successful subtalar joint arthrodesis provides pain relief, resultant alterations in ankle biomechanics need to be considered, as this procedure may predispose the remaining hindfoot and tibiotalar joint to accelerated degenerative changes. However, the biomechanical consequences of isolated subtalar joint arthrodesis
\end{abstract}

Each author certifies that he or she, or a member of their immediate family, has no commercial associations (eg, consultancies, stock ownership, equity interest, patent/licensing arrangements, etc) that might pose a conflict of interest in connection with the submitted article.

All ICMJE Conflict of Interest Forms for authors and Clinical Orthopaedics and Related Research ${ }^{\mathbb{R}}$ editors and board members are on file with the publication and can be viewed on request.

Clinical Orthopaedics and Related Research ${ }^{\mathbb{B}}$ neither advocates nor endorses the use of any treatment, drug, or device. Readers are encouraged to always seek additional information, including FDAapproval status, of any drug or device prior to clinical use. This work was performed at the Department of Biomechanics, Hospital for Special Surgery, New York, NY, USA.

Ian D. Hutchinson and Josh R. Baxter have equally contributed to this work.

I. D. Hutchinson, J. R. Baxter, S. Gilbert, H. Wang

Department of Biomechanics, Hospital for Special Surgery, New

York, NY, USA

M. V. Hogan, S. M. Saunders, J. G. Kennedy ( $\square)$

Department of Foot and Ankle Surgery, Hospital for Special

Surgery, 523 East 72nd Street, New York, NY 10021, USA

e-mail: kennedyj@hss.edu

M. V. Hogan

Division of Foot and Ankle Surgery, Department of Orthopaedic Surgery, University of Pittsburgh Medical Center, Pittsburgh, PA, USA and additive fusions of the Chopart's joints on tibiotalar joint biomechanics remain poorly understood.

Questions/purposes We asked: What is the effect of isolated subtalar fusion and sequential Chopart's joint fusions of the talonavicular and calcaneocuboid joints on tibiotalar joint (1) mechanics and (2) kinematics during loading for neutral, inverted, and everted orientations of the foot?

Methods We evaluated the total force, contact area, and the magnitude and distribution of the contact stress on the articular surface of the talar dome, while simultaneously tracking the position of the talus relative to the tibia during loading in seven fresh-frozen cadaver feet. Each foot was loaded in the unfused, intact control condition followed by three randomized simulated hindfoot arthrodesis modalities: subtalar, double (subtalar and talonavicular), and triple (subtalar, talonavicular, and calcaneocuboid) arthrodesis. The intact and arthrodesis conditions were tested in three alignments using a metallic wedge insert: neutral (flat), $10^{\circ}$ inverted, and $10^{\circ}$ everted.

Results Tibiotalar mechanics (total force and contact area) and kinematics (external rotation) differed owing to hindfoot arthrodeses. After subtalar arthrodesis, there were

\section{J. Ling}

Prince of Wales, Sydney Children's Hospitals, Sydney Orthopaedic Specialists Foot and Ankle Institute, Sydney, Australia 
decreases in total force $(445 \pm 142 \mathrm{~N}, 95 \% \mathrm{CI}, 340-550 \mathrm{~N}$, versus $588 \pm 118 \mathrm{~N}, 95 \% \mathrm{CI}, 500-676 \mathrm{~N} ; \mathrm{p}<0.001)$ and contact area $\left(282 \mathrm{~mm}^{2}, 95 \% \mathrm{CI}, 222-342 \mathrm{~mm}^{2}\right.$, versus 336 $\left.\pm 96 \mathrm{~mm}^{2}, 95 \% \mathrm{CI}, 265-407 \mathrm{~mm}^{2} ; \mathrm{p}<0.026\right)$ detected during loading in the neutral position; these changes also were seen in the everted foot position. Hindfoot arthrodesis also was associated with increased external rotation of the tibiotalar joint during loading: subtalar arthrodesis in the neutral loading position $\left(3.3^{\circ} \pm 1.6^{\circ} ; 95 \% \mathrm{CI}, 2^{\circ}-4.6^{\circ} ; \mathrm{p}=\right.$ $0.004)$ and everted loading position $\left(4.8^{\circ} \pm 2.6^{\circ} ; 95 \% \mathrm{CI}\right.$, $\left.2.7^{\circ}-6.8^{\circ} ; \mathrm{p}=0.043\right)$; double arthrodesis in neutral $\left(4.4^{\circ} \pm\right.$ $\left.2^{\circ} ; 95 \% \mathrm{CI}, 2.8^{\circ}-6^{\circ} ; \mathrm{p}=0.003\right)$ and inverted positions $\left(5.8^{\circ} \pm 2.6^{\circ} ; 95 \% \mathrm{CI}, 3.7^{\circ}-7.9^{\circ} ; \mathrm{p}=0.002\right)$, and triple arthrodesis in all loaded orientations including neutral (4.5 $\left.\pm 1.8^{\circ} ; 95 \% \mathrm{CI}, 3.1^{\circ}-5.9^{\circ} ; \mathrm{p}=0.002\right)$, inverted $\left(6.4^{\circ} \pm\right.$ $\left.3.5^{\circ} ; 95 \% \mathrm{CI}, 3.6^{\circ}-9.2^{\circ} ; \mathrm{p}=0.009\right)$, and everted $\left(3.6^{\circ} \pm\right.$ $\left.2^{\circ} ; 95 \% \mathrm{CI}, 2^{\circ}-5.2^{\circ} ; \mathrm{p}=0.053\right)$ positions. Finally, after subtalar arthrodesis, additive fusions at Chopart's joints did not appear to result in additional observed differences in tibiotalar contact mechanics or kinematics with the number of specimens available.

Conclusions Using a cadaveric biomechanical model, we identified some predictable trends in ankle biomechanics during loading after hindfoot fusion. In our tested specimens, fusion of the subtalar joint appeared to exert a dominant influence over ankle loading.

Clinical Relevance A loss or deficit in function of the subtalar joint may be sufficient to alter ankle loading. These findings warrant consideration in the treatment of the arthritic hindfoot and also toward defining biomechanical goals for ankle arthroplasty in the setting of concomitant hindfoot degeneration or arthrodesis.

\section{Introduction}

Isolated subtalar arthrodesis is the preferred procedure in patients with clinical and radiographic arthritis confined to the subtalar joint that is refractory to conservative treatment $[11,14,18,24]$. Additive fusions of the talonavicular and calcaneocuboid joints, resulting in double [29] and triple arthrodeses [28, 31], respectively, are done when arthritic joint changes, deformity and symptoms clearly extend to the midtarsal joints (Chopart's).

Although successful subtalar joint arthrodesis provides pain relief, resultant alterations in ankle biomechanics need to be considered carefully given the possibility that this procedure may predispose the remaining hindfoot and ankle to accelerated degenerative changes $[8,19,21,23,25]$. The clinical association among subtalar joint arthrodesis, double (subtalar and talonavicular), and triple (subtalar, talonavicular, and calcaneocuboid) arthrodeses with progressive ankle degeneration is evident in medium- to long-term clinical studies [13,
18, 24]. In addition, diminished hindfoot function owing to subtalar joint arthrodesis may change the biomechanical goals of total ankle arthroplasty by potentially displacing the load distribution in the joint and by subjecting the situated replacement to altered kinematics during loading. Currently, the specific biomechanical consequences of subtalar arthrodesis and sequential Chopart's joint arthrodesis on ankle biomechanics remain speculative and poorly understood.

Existing biomechanical models investigating the effect of hindfoot arthrodeses on ankle biomechanics have shown increased contact stresses in the ankle after triple arthrodesis; in the same model, isolated subtalar arthrodesis was not shown to alter ankle contact mechanics $[33,34]$. However, these biomechanical studies were done using an experimental model that simulated flat ground loading that resembles the stance phase of gait with the foot in the neutral position. Variations in loading during inversion and eversion of the foot are commonly encountered and result in compensatory alterations in gait patterns in healthy subjects $[9,10]$. In addition, flat ground-loading models do not examine the foot and ankle complex in the frontal (coronal) plane where the subtalar joint contributes to maintain lower limb alignment with a loaded plantar foot position [5]. Subsequently, provocative loading conditions (inverted and everted orientations of the foot) are warranted to capture alterations in ankle biomechanics after arthrodesis of the hindfoot.

Therefore, we asked: what is the effect of isolated subtalar fusion and sequential Chopart's joint fusions on tibiotalar (1) mechanics and (2) kinematics during loading for neutral, inverted, and everted orientations of the foot?

\section{Materials and Methods}

Seven fresh-frozen cadaveric lower limbs were used in this study. Specimens were unpaired and had a mean age of 59 years (45-69 years; five left feet and five male donors) and were stored in a $-20^{\circ} \mathrm{C}$ freezer before testing. Specimens showing obvious hindfoot deformity or osteoarthritic changes in the ankle were excluded from the study. For each specimen, the interosseous membrane was dissected carefully and spared to allow accurate positioning of a fixation screw from the tibia to the fibula to maintain the anatomy before truncation. Each specimen was truncated at the level of the midshaft tibia, approximately $20 \mathrm{~cm}$ above the tibial plafond, and all soft tissues, excluding the origin of the ankle ligaments and the Achilles tendon, were removed. The proximal exposed tibia was potted in a cylinder of bonding cement (Bondo ${ }^{\mathbb{R}} ; 3 \mathrm{M}$, Atlanta, GA, USA). The joint capsule was exposed anteriorly, taking care to preserve the adjacent ankle ligamentous structures. A transverse $1-\mathrm{cm}$ incision in the posterior capsule, slitting 
the fibers of the posterior intermalleolar ligament, allowed for posterior fixation of additional leaflets applied to the sensor to serve as points of attachment, anteriorly and posteriorly. The Achilles tendon was sutured to a nylon strap using a \#2 nylon suture (Ethicon, Somerville, NJ, USA). After preparation, each specimen was secured to a hydraulic testing frame (Bionix ${ }^{\mathbb{R}} 858$; MTS, Eden Prairie, MN, USA), while the foot was positioned at $0^{\circ}$ dorsiflexion (Fig. 1). The Achilles tendon strap was routed over a pulley and fastened to a pneumatic cylinder. Therefore, during loading, there was restriction of axial rotation of the tibia, prompting motion of the ankle and hindfoot complex to facilitate loading. The specimens were hydrated continuously using normal saline solution: on the testing device we used a sprayer and rubbed the hydrating fluid into the tissue, and when the specimens were awaiting testing they were wrapped carefully in saline-soaked gauze.

Specimens were first tested in an intact state and then sequential testing was randomized with respect to arthrodesis condition and orientation of the foot. Subtalar, double (subtalar and talonavicular), and triple (subtalar, talonavicular, and calcaneocuboid) arthrodesis conditions were tested by applying fixation methods to simulate arthrodeses. Randomization of the testing conditions was

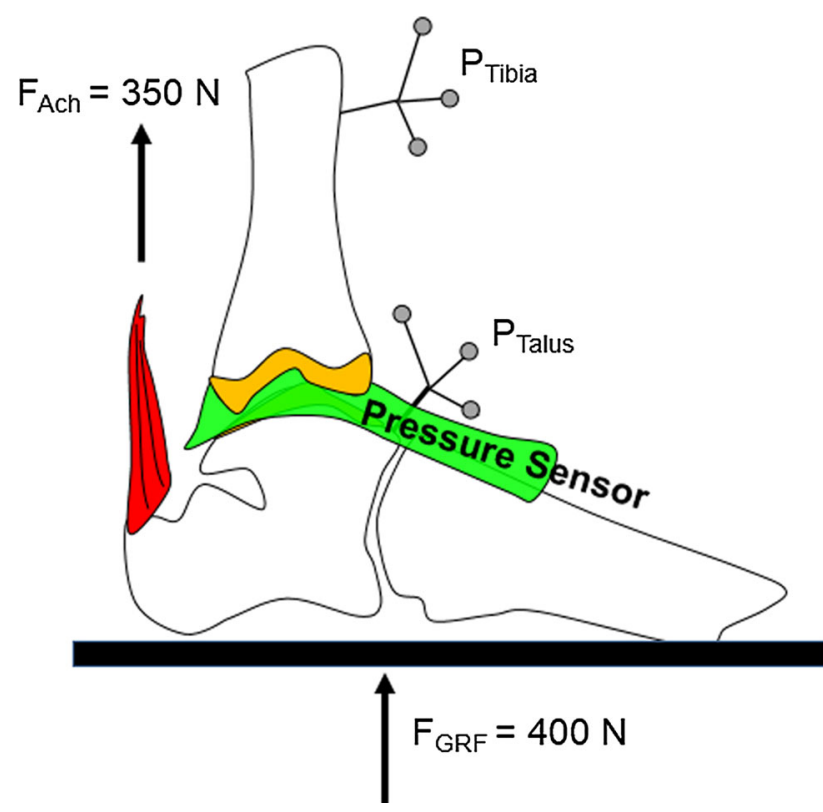

Fig. 1 The experimental loading setup was comprised of an axial loading system using a hydraulic testing frame and hydraulic Achilles tendon tensioning (red) which created Achilles force $\left(\mathrm{F}_{\mathrm{ACH}}\right)$ resulting in an equal ground reaction force $\left(\mathrm{F}_{\mathrm{GRF}}\right)$ using a customized pulley system with a load cell positioned in series. An electronic pressure sensor was positioned in the ankle (green) covering the talar dome, juxtaposed to the tibial cartilage (yellow). The relative movements of the tibia and talus $\left(\mathrm{P}_{\text {Tibia }}\right.$ and $\left.\mathrm{P}_{\text {Talus }}\right)$ were recorded using a motion capture system. achieved by creating definitive subtalar fusion and reversible fusion(s) of the talonavicular and calcaneocuboid joints using bone staples. For the intact state (and each arthrodesis condition), specimens were tested in three frontal plane orientations: neutral position, $10^{\circ}$ eversion, and $10^{\circ}$ inversion (Fig. 2). This foot position was prescribed using an aluminum wedge with a $10^{\circ}$ slope. The 12 test conditions were loaded based on a previously described loading regime [3, 20]: a $400-\mathrm{N}$ ground reaction force was achieved and maintained from an axial load applied along the axis of the tibia and a 350-N tensile load along the Achilles tendon through a pneumatic cylinder (Fig. 1). The 400-N ground reaction force represented $1 / 2$ body weight of a standardized 800-N (approximately 180 pounds) individual, whereas the Achilles tendon load transferred load through the midfoot, which is common in standing $[1,2,12,26]$. Body weight was standardized to optimize the reproducibility of the experimental setup to apply and detect prescribed loads.

\section{Hindfoot Fusion Model}

Subtalar fixation to simulate arthrodesis was performed by foot and ankle fellows using two 7-mm cannulated compression screws (TriMed ${ }^{\mathbb{R}}$, Santa Clarita, CA, USA). The subtalar joint was fused with a surgical goal of a $0^{\circ}$ to $5^{\circ}$ everted hindfoot position encompassing the variability of clinically used surgical approaches and avoiding extremes of valgus and varus [17]. Loaded kinematic measurements of the talus-calcaneus complex after subtalar arthrodesis were used to confirm hindfoot orientation. Specimens ranged between $0.6^{\circ}$ inversion to $5.5^{\circ}$ eversion (mean, $1.5^{\circ}$ everted/valgus). Simulated fusion of the talonavicular and calcanocuboidal joint was achieved using two bone staples across each joint and anatomic position was confirmed in the neutral position by direct observation [27]. The articular surfaces were not denuded to allow randomization of the fusion conditions. Before each testing cycle, the fusions were physically examined for integrity between conditions.

\section{Contact Mechanics}

Ankle contact stresses were measured using thin pressure sensitive film (Model 5033; Tekscan ${ }^{\circledR}$ Inc, South Boston, MA, USA) inserted through an incision in the anterior capsule of the ankle (Fig. 2). The area of the matrix was 27 $\mathrm{mm} \times 38 \mathrm{~mm}$ and was calibrated at $20 \%$ and $80 \%$ of the estimated ankle loading of $750 \mathrm{~N}$ [6]. The area of the matrix was $26.7 \mathrm{~mm} \times 38.4 \mathrm{~mm}$, which consisted of 1472 sensels (sensing elements) with spatial resolution of 0.8 $\mathrm{mm} \times 0.8 \mathrm{~mm}$. Sensor drift was monitored during the 


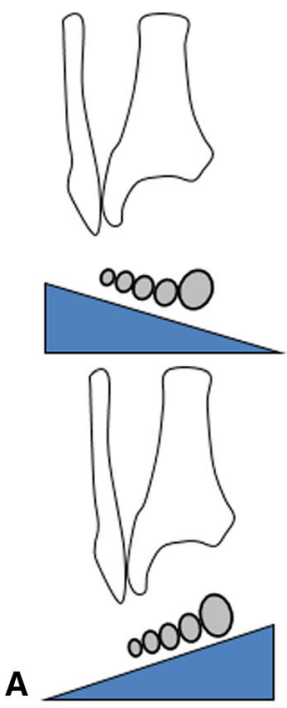

B

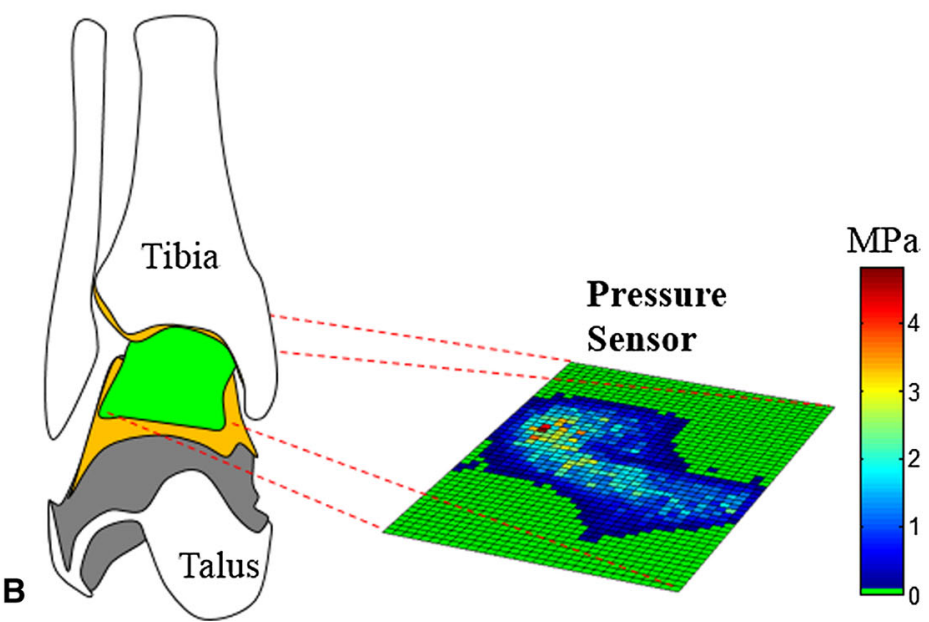

Fig. 2A-B (A) A metal wedge (blue) was used to achieve the everted and inverted loaded foot position is shown. (B) Contact mechanics were measured using a thin electronic pressure sensor (green) that

study at the end of testing when a prescribed standard load was applied using the MTS testing frame. We observed no effect of elapsed time on sensor output when we applied a $750-\mathrm{N}$ compressive load on a single sensor every 15 minutes for 8 hours. The normal contact stress across the talus cartilage surface was exported to a custom MATLAB ${ }^{\circledR}$ program (MathWorks ${ }^{\circledR}$ Inc, Natick, MA, USA) for analysis [38]. Contact area, mediolateral position of the weighted center of contact (WCoC, equation 1), total contact force, absolute peak stress, and mean contact stress were calculated for each testing condition. Although the center of contact is stress magnitude-independent, the WCoC takes into account the locations and magnitude of the contact stresses and therefore is influenced less by smaller stresses that occur at the periphery of the joint; this technique was developed to characterize joint loading in static and dynamic cadaveric knee models [37, 39]:

$W C o C=\sum_{i=1}^{n}\left(s_{i} \times p_{i}\right) / \sum_{i=1}^{n} s_{i}$

where $s_{i}$ denotes the contact stress at sensel- $i$ and $p_{i}$ denotes the sensel position in the local coordinate system. The location of WCoC along the mediolateral direction was determined using this method.

\section{Ankle Position}

Ankle kinematics were recorded during each test condition with a four-camera motion capture system (Eagle-4 cameras; Motion Analysis Corp, Santa Rosa, CA, USA) to detect joint position during loading. Reflective markers overlaid the talar cartilage (yellow). The output produced colorimetric contact stress maps as projected to the right.

were rigidly secured to the tibia and talus (Fig. 1), and a custom MATLAB ${ }^{\circledR}$ routine calculated ankle orientation as recommended by the International Society of Biomechanics [40]. In brief, the transmalleolar axis defined the dorsiflexion and plantar flexion axes, the line perpendicular to the frontal plane of the tibia defined inversion and eversion, and the common line perpendicular to these two axes defined internal and external rotation. Neutral ankle position was calculated as the angles measured while the intact foot was loaded in a neutral position. All subsequent ankle positions were compared with these angles. ROM in the frontal and transverse planes was determined as the difference in absolute joint position between the testing orientations of the foot.

\section{Validation of the Experimental Model}

Before experimental testing, we conducted a pilot study to investigate the ability of our fixation techniques to recreate the requisite stability required to simulate joint arthrodesis. After preconditioning, we performed a full testing regime and tracked the motion of all the "fused" hindfoot bones (talus, cuboid, navicular and calcaneus) relative to each other to evaluate joint fixation during loading. We confirmed that our fixation techniques could constrain the motion between the "fused" bones of the hindfoot joints to less than $1 \mathrm{~mm}$ and $1^{\circ}$ translation and rotation using quasistatic kinematic measures during the neutral, inverted, and everted loaded foot positions. We found this to be acceptable for our study.

Finally, during experimental testing, contact mechanics and kinematics of the tibiotalar joint in the intact, unfused 


\section{Contact Force}

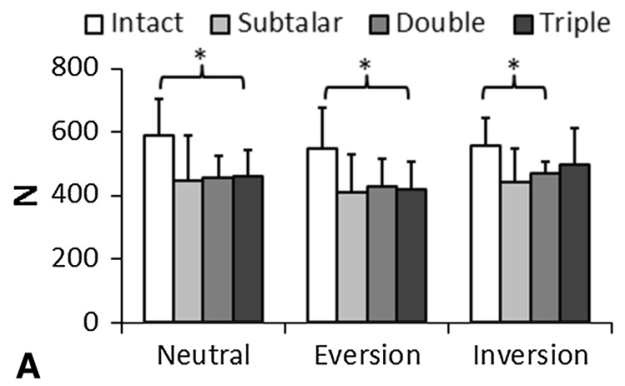

Contact Area

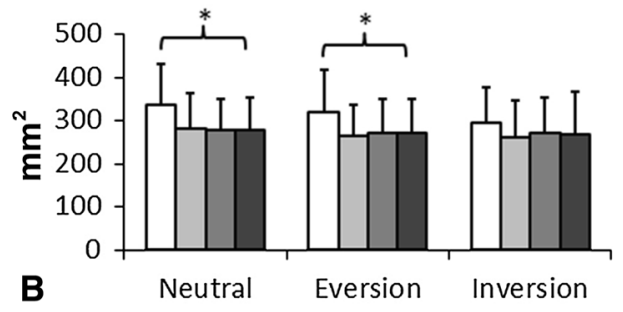

Peak Contact Stress

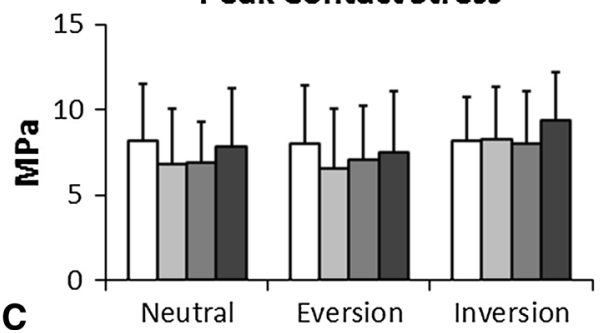

Fig. 3A-C Contact mechanics and kinematics of the tibiotalar joint are shown for (A) peak contact stress, (B) total force transmitted by the talar dome, and $(\mathbf{C})$ total contact area. Standard deviations are described with $*$ denoting $\mathrm{p}$ less than 0.05 .

condition of each specimen (with a functioning hindfoot) remained similar between neutral loading and loading in the inverted and everted foot positions (Fig. 3). In addition, placement of the sensor on the talar dome detected: neutral position $78 \%(588 \pm 118 \mathrm{~N})$; everted position $73 \%$ (549 \pm $127 \mathrm{~N})$ and inverted position $74 \%(556 \pm 90 \mathrm{~N})$ of the combined load $(750 \mathrm{~N})$ applied axially and through the Achilles tendon (Fig. 1).

\section{Statistical Analysis}

Differences in contact stress parameters and ankle kinematics between the intact and three fusion conditions at each foot position were assessed using a repeated-measure ANOVA model. Statistical significance was set at $\alpha=0.05$ and all analyses were performed using the MATLAB ${ }^{\circledR}$ Statistics Toolbox. Tukey's post hoc analyses were done to confirm observed variance. To determine if our study had sufficient power to detect our findings in the number of tested specimens, we performed a post hoc power analysis using an alpha of 0.05 and a sample size of seven for the mechanics and six for the kinematics. This analysis revealed that the power of our study was sufficient to detect the decrease in force (0.99, four samples required), decrease in area (0.77, eight samples required), and increase in external rotation (0.99, five samples required) between the intact and the subtalar arthrodesis conditions in the neutral loading position.

\section{Results}

Mechanics

After subtalar arthrodesis, contact area and total force detected by the sensor on the articulating surface of the talar dome were decreased in the neutral and everted loading positions for the seven tested specimens (Fig. 3AB) (Table1). Overall, these changes remained consistent for isolated subtalar arthrodesis and double and triple arthrodeses.

Despite remaining in the same fixed position on the articular surface of the talar dome throughout the testing conditions, the load detected was decreased compared with the unfused, intact condition in the neutral position after subtalar arthrodesis by $24 \%(445 \pm 142 \mathrm{~N} ; 95 \%$ CI, 340 $550 \mathrm{~N} ; \mathrm{p}<0.001)$; double arthrodesis by $22 \%(457 \pm 67$ $\mathrm{N} ; 95 \% \mathrm{CI}, 351-561 \mathrm{~N} ; \mathrm{p}=0.002$ ), and triple arthrodesis by $21 \%(462 \pm 83 \mathrm{~N} ; 95 \% \mathrm{CI}, 400-524 \mathrm{~N} ; \mathrm{p}=0.002)$ (Fig. 3A). In the everted loaded position, detected load also was decreased for subtalar arthrodesis by $30 \%(411 \pm 117$ $\mathrm{N} ; 95 \% \mathrm{CI}, 324-498 \mathrm{~N} ; \mathrm{p}<0.001)$; double arthrodesis by $27 \%(430 \pm 87 \mathrm{~N} ; 95 \% \mathrm{CI}, 365-495 \mathrm{~N} ; \mathrm{p}=0.002)$, and triple arthrodesis by $29 \%(418 \pm 89 \mathrm{~N} ; 95 \% \mathrm{CI}, 352-484$ $\mathrm{N} ; \mathrm{p}<0.001)$. Finally, in the inverted foot position, total force was decreased by $25 \%$ after subtalar arthrodesis (440 $\pm 108 \mathrm{~N} ; 95 \% \mathrm{CI}, 359-521 \mathrm{~N} ; \mathrm{p}=0.023)$ and double arthrodesis by $20 \%(468 \pm 40 \mathrm{~N} ; 95 \% \mathrm{CI}, 438-497 \mathrm{~N} ; \mathrm{p}=$ 0.023).

Contact area decreased during neutral loading compared with the unfused, intact condition for subtalar arthrodesis by $16 \%\left(282 \pm 81 \mathrm{~mm}^{2}\right.$; $95 \% \mathrm{CI}, 222-342 \mathrm{~mm}^{2}$; $\mathrm{p}=$ $0.026)$; double arthrodesis by $17 \%\left(279 \pm 76 \mathrm{~mm}^{2} ; 95 \%\right.$ CI, 241-347 $\left.\mathrm{mm}^{2} ; \mathrm{p}=0.007\right)$, and triple arthrodesis by $17 \%\left(279 \pm 74 \mathrm{~mm}^{2} ; 95 \% \mathrm{CI}, 224-234 \mathrm{~mm}^{2} ; \mathrm{p}=0.018\right)$ (Fig. 3B). In addition, contact area was reduced compared with the unfused condition during loading in the everted foot position for subtalar arthrodesis by 18\% (264 \pm 73 $\mathrm{mm}^{2} ;$ 95\% CI, 209-319 $\left.\mathrm{mm}^{2} ; \mathrm{p}=0.009\right)$; double arthrodesis by $15 \%\left(271 \pm 81 \mathrm{~mm}^{2} ; 95 \% \mathrm{CI}, 211-331\right.$ $\left.\mathrm{mm}^{2} ; \mathrm{p}=0.005\right)$, and triple arthrodesis by $20 \%(271 \pm 79$ 


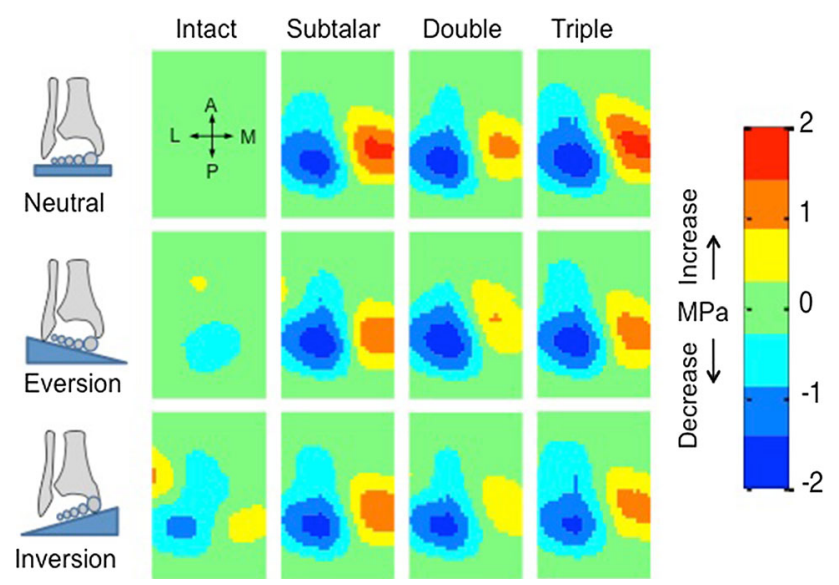

Fig. 4 In the intact ankle, contact stresses were qualitatively slightly altered at eversion and inversion. After fusion, there was a qualitative trend toward a decrease at the lateral aspect and an increase at the medial aspect of the joint. Double and triple arthrodeses resulted in similar effect on the distribution of contact stresses.

$\left.\mathrm{mm}^{2} ; 95 \% \mathrm{CI}, 212-330 \mathrm{~mm}^{2} ; \mathrm{p}=0.006\right)$. Contextually, in the unfused, intact feet our model showed no difference in contact area of $5 \%\left(320 \pm 97 \mathrm{~mm}^{2} ; \mathrm{p}=0.040\right)$ in the everted foot and $11 \%\left(297 \pm 81 \mathrm{~mm}^{2} ; \mathrm{p}=0.006\right)$ in the inverted foot positions compared with loading of the neutrally aligned foot.

The location of contact stress remained relatively fixed between the loading conditions after subtalar arthrodesis (Fig. 4). Finally, coincident with a decrease in total force and contact area after hindfoot arthrodesis, peak contact stress and mean stress measurements did not change in our specimens (Fig. 3C).

\section{Kinematics}

Loading after subtalar arthrodesis resulted in the tibiotalar joint becoming more externally rotated during loading in the six specimens where the kinematics were captured successfully (Fig. 5) (Table 1). For subtalar arthrodesis, the tibiotalar joint was more externally rotated in the neutral loading position $\left(3.3^{\circ} \pm 1.6^{\circ} ; 95 \% \mathrm{CI}, 2^{\circ}-4.6^{\circ} ; \mathrm{p}<\right.$ $0.004)$ and the everted loading position $\left(4.8^{\circ} \pm 2.6^{\circ} ; 95 \%\right.$ CI, $2.7^{\circ}-6.8^{\circ} ; \mathrm{p}=0.043$ ). After triple arthrodesis the tibiotalar joint became more externally rotated in all loaded orientations: neutral $\left(4.5^{\circ} \pm 1.8^{\circ} ; 95 \% \mathrm{CI}, 3.1^{\circ}-5.9^{\circ} ; \mathrm{p}=\right.$ $0.02)$; inverted position $\left(6.4^{\circ} \pm 3.5^{\circ} ; 95 \% \mathrm{CI}, 3.6^{\circ}-9.2^{\circ} ; \mathrm{p}\right.$ $=0.009)$; and everted position $\left(3.6^{\circ} \pm 2^{\circ} ; 95 \% \mathrm{CI}, 2^{\circ}-5.2^{\circ}\right.$; $\mathrm{p}=0.053)$.

Regarding frontal plane joint position and motion, there was no demonstrable difference in the loaded position of the tibiotalar joint after hindfoot fusion compared with the unfused condition. In general, specimens showed variation

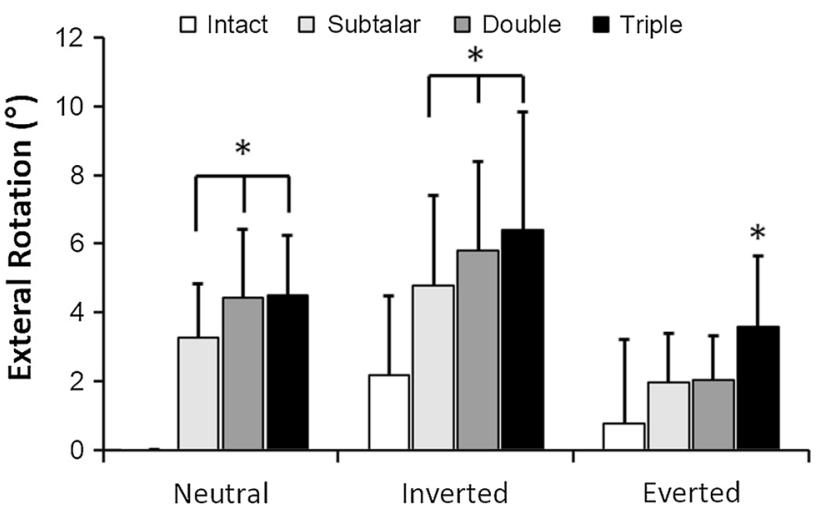

Fig. 5 The transverse plane ankle position during prescribed loading conditions is shown Standard deviations with * denoting p less than 0.05 to the neutral, unfused condition are shown.

Table 1. Statistical analysis of experimental conditions

\begin{tabular}{lclc}
\hline $\begin{array}{l}\text { Outcome } \\
\text { measures }\end{array}$ & $\begin{array}{l}\text { Subtalar } \\
\text { arthrodesis }\end{array}$ & $\begin{array}{l}\text { Double } \\
\text { arthrodesis }\end{array}$ & $\begin{array}{l}\text { Triple } \\
\text { arthrodesis }\end{array}$ \\
\hline Contact area & & & 0.018 \\
Neutral & 0.026 & 0.007 & 0.006 \\
$\begin{array}{l}\text { Everted } \\
\text { Inverted }\end{array}$ & 0.009 & 0.005 & 0.087 \\
Total contact force & 0.169 & 0.104 & 0.002 \\
Neutral & $<0.001$ & 0.002 & $<0.001$ \\
Everted & $<0.001$ & 0.002 & 0.3 \\
Inverted & 0.023 & 0.023 & 0.66 \\
Peak contact stress & & & 0.317 \\
Neutral & 0.038 & 0.065 & 0.104 \\
Everted & 0.126 & 0.272 & 0.002 \\
Inverted & 0.822 & 0.852 & 0.053 \\
External rotation & & 0.003 & 0.009 \\
Neutral & 0.004 & 0.185 & \\
Everted & 0.091 & 0.044 & \\
Inverted & 0.043 & & \\
\hline P values refect & & &
\end{tabular}

$\mathrm{P}$ values reflect comparison of each experimental condition with the intact (unfused) foot.

in absolute joint position and ROM in the three tested foot positions for the intact condition $\left(1.43^{\circ} \pm 0.46^{\circ}\right)$ and after subtalar fusion $\left(1.64^{\circ} \pm 1.4^{\circ}\right)$; however, there was no evidence of any consistent trends using our model and with the numbers of specimens available (Fig. 6).

\section{Discussion}

Reported rates of postoperative ankle degeneration after isolated subtalar fusion or triple arthrodesis are variable in the literature; however long-term studies ( $>10$ years) comparing the rates of osteoarthritic progression in the 


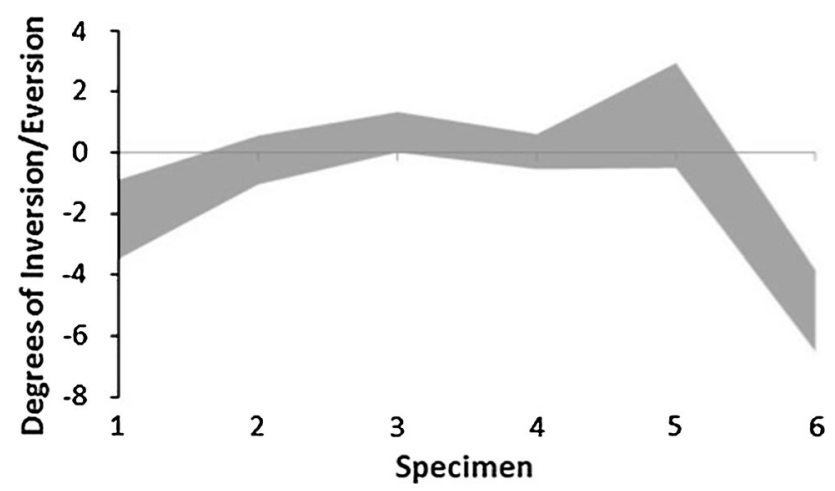

Fig. 6 Frontal plane kinematics showed some variation in absolute joint position between specimens during loading. The continuous grey scale across specimens denotes the range of frontal plane motion exhibited when the specimens were subjected to the neutral, everted, and inverted loading positions after subtalar fusion.

ankle have been equivocal and abnormal joint mechanics have been implicated [13, 15]. Therefore, our controlled laboratory study aimed to describe and relate the biomechanical consequences of subtalar, double, and triple arthrodeses in the tibiotalar joint by applying these hindfoot fusion modalities to the same cadaveric feet and the randomizing testing conditions. Using a biomechanical model mimicking standing, we tested seven feet with randomized hindfoot arthrodeses (isolated subtalar, double, and triple arthrodeses) in neutral, inverted, and everted foot positions. In our model and with the number of specimens available, hindfoot arthrodesis did not result in increased contact stresses (localized or generalized) on the articular surface of the talar dome. Rather, the distribution of contact stresses became relatively fixed over a smaller area with decreased total force detected despite consistent axial and Achilles tendon loading and sensor placement. Our findings also suggested that subtalar fusion and additional arthrodeses of the Chopart's joints resulted in increased external rotation of the tibiotalar joint during loading.

Our study has limitations that warrant discussion in the context of interpreting the results. Static testing of cadaver limbs may not be representative of normal loading during dynamic activities and only offers insight into joint function and an interaction using simplified loading scenarios. In addition, our study was inadequately powered to compare the fusion modalities directly with each other regarding the outcome variables. The experimental apparatus applied an axial force to the tibia (and rigidly fixed fibula) without the capacity for physiologic transverse plane torque. In addition, although the Achilles tendon was loaded, the other extrinsic tendons were sectioned proximal to the ankle, but these tendon loads are very small compared with Achilles tension during locomotion [2]. However, in vitro biomechanical testing offers an important insight by allowing the investigator to prescribe precise loads and to control for variations in anatomy by applying sequential fusions and testing in individual specimens. In addition, invasive direct measures of joint contact mechanics and kinematics are readily achievable.

Radiographic confirmation of subtalar fusion position was not done; instead, kinematic positional assessment of the talus-calcaneus fused complex relative to the tibia was compared with the unfused condition to assess neutrally loaded hindfoot alignment. In addition, while we validated our fixation system to simulate hindfoot fusions, also using positional assessment of the hindfoot bones, we do not suggest that this is exactly as robust as a solid bony fusion. As discussed above, we applied the same loads to each specimen to standardize testing in our loading and loaddetecting systems, mindful that the body weights recorded at the end of life may not be representative of the actual body weights of the donors during their more active years. Finally, we did not apply pressure sensors to the medial and lateral gutters of the tibiotalar joint, limiting our ability to detect the loads that appeared to be displaced from the articular surface of the talar dome after subtalar arthrodesis.

Loading of the unfused foot resulted in $75 \%$ of the applied load detected by the pressure sensor on the talar dome in each loading position, consistent with previous studies [4, 34]. Applied loading in the inverted and everted foot positions has been associated with variation in the mediolateral location of contact in the ankle in unfused, intact feet; such changes in contact location were not significant in our tested specimens (Fig. 4) [7]. However, after subtalar fusion, we observed a decrease in total force detected by the sensor and contact patterns and distribution became relatively fixed between each loading condition. Given that our testing conditions were randomized and that our sensors experienced minimal drift during testing, load transfer across the ankle likely occurred in an area not covered by our electronic sensor and may be the result of loss of congruence of the loaded joint resulting from decreased hindfoot motion. Altered force transmission across the ankle, also seen in an extrinsic tendon-loading study, warrants additional study, particularly in the consideration of ankle replacement technologies for patients with hindfoot dysfunction or fusion [34].

Ankle position showed no variation in the transverse plane during loading despite the fixed potted tibia-fibula complex and lack of coupled tibial rotation during loading (Fig. 5). Loading of feet with a fused subtalar joint (loss of the subtalar axis) in the neutral position resulted in increased external rotation of the ankle. During inverted loading, subtalar and double fusion caused abnormal external rotation and only triple fusion resulted in increased everted ankle rotation in the everted loaded foot position 
(Fig. 6). At the subtalar joint, inversion is coupled to internal rotation and eversion is coupled to external rotation, and it has been speculated that loss of subtalar joint function could result in increased rotational forces at the ankle $[22,30,36]$. The subtalar joint behaves like a flexible structure through the ROM and is critical in the transmission of rotational forces from the foot to the lower leg [22]. In the ankle, the articular surfaces act as primary stabilizers against excessive talar rotation and translation when the ankle complex is fully loaded contributing to passive ankle stabilization $[32,35]$. The trochlear surface of the talus was modeled as a skewed truncated conic saddle shape with its apex oriented laterally providing stable congruency in movements of inversion and eversion [30]. We observed some variability in absolute frontal plane ankle position between specimens; however, ROM in the frontal plane during loading was similar in all specimens throughout the study for each loaded position (Fig. 6). Although the specific effects of morphologic features of the talar dome on stability remain unclear, contact mechanics (force, contact area) were maintained only during neutral, everted, and inverted loading positions of the intact, unfused foot, suggesting that frontal plane motion in the hindfoot joints may contribute to ankle congruency. After hindfoot fusion, loading resulted in an externally rotated ankle representing a potential mechanism or consequence of ankle stabilization without a functioning hindfoot. Consistency of ankle contact mechanics between inverted and everted loaded positions precludes lateral impingement as a confounding factor after subtalar fusion.

It is possible that hindfoot fusion modalities have the potential to produce different results in different individuals given the strong dependency of passive joint mechanics on morphologic features of the ankle complex [16]. However, our simplified model identified some predictable trends in ankle biomechanics during loading after hindfoot fusion. Despite the lack of increases in contact stress measurements seen in our study, altered ankle loading during dynamic activities warrant further investigation to complement these findings and to fully investigate the pathomechanics implicated in premature ankle degeneration after hindfoot arthrodesis [8, 21, 25]. Specifically, additional research is warranted to investigate the role of the medial and lateral gutters in load dissipation at the ankle after loss of hindfoot function. In addition, radiographic analysis and implant retrieval of ankle replacements may allude to differential loading with hindfoot fusion or advanced arthrosis. Finally, it is worth considering that in patients with ankle replacements, progressive degeneration of the subtalar joint with resultant loss of function may have the potential to change the biomechanical demands on the implant with time.
Acknowledgments We thank Carl Imhauser PhD (Department of Biomechanics, Hospital for Special Surgery, New York, NY, USA), and Ethan Fraser MD and Ashraf Fansa MD (both from the Department of Foot and Ankle Surgery, Hospital for Special Surgery) for their valuable input in planning and performance of the study.

\section{References}

1. Astion DJ, Deland JT, Otis JC, Kenneally S. Motion of the hindfoot after simulated arthrodesis. J Bone Joint Surg Am. 1997;79:241-246.

2. Baxter JR, Demetracopoulos CA, Prado MP, Gilbert SL, Tharmviboonsri T, Deland JT. Graft shape affects midfoot correction and forefoot loading mechanics in lateral column lengthening osteotomies. Foot Ankle Int. 2014;35:1192-1199.

3. Baxter JR, Demetracopoulos CA, Prado MP, Tharmviboonsri T, Deland JT. Lateral column lengthening corrects hindfoot valgus in a cadaveric flatfoot model. Foot Ankle Int. 2015;36:705-709.

4. Beaudoin AJ, Fiore SM, Krause WR, Adelaar RS. Effect of isolated talocalcaneal fusion on contact in the ankle and talonavicular joints. Foot Ankle. 1991;12:19-25.

5. Beimers L, Tuijthof GJ, Blankevoort L, Jonges R, Maas M, van Dijk CN. In-vivo range of motion of the subtalar joint using computed tomography. J Biomech. 2008;41:1390-1397.

6. Brimacombe JM, Wilson DR, Hodgson AJ, Ho KC, Anglin C. Effect of calibration method on Tekscan sensor accuracy. $J$ Biomech Eng. 2009;131:034503.

7. Calhoun JH, Li F, Ledbetter BR, Viegas SF. A comprehensive study of pressure distribution in the ankle joint with inversion and eversion. Foot Ankle Int. 1994;15:125-133.

8. Chen CT, Bhargava M, Lin PM, Torzilli PA. Time, stress, and location dependent chondrocyte death and collagen damage in cyclically loaded articular cartilage. J Orthop Res. 2003;21:888898.

9. Damavandi M, Dixon PC, Pearsall DJ. Kinematic adaptations of the hindfoot, forefoot, and hallux during cross-slope walking. Gait Posture. 2010;32:411-415.

10. Damavandi M, Dixon PC, Pearsall DJ. Ground reaction force adaptations during cross-slope walking and running. Hum Move Sci. 2012;31:182-189.

11. Davies MB, Rosenfeld PF, Stavrou P, Saxby TS. A comprehensive review of subtalar arthrodesis. Foot Ankle Int. 2007;28:295297.

12. De Cock A, Vanrenterghem J, Willems T, Witvrouw E, De Clercq D. The trajectory of the centre of pressure during barefoot running as a potential measure for foot function. Gait Posture. 2008;27:669-675.

13. de Heus JA, Marti RK, Besselaar PP, Albers GH. The influence of subtalar and triple arthrodesis on the tibiotalar joint: a longterm follow-up study. J Bone Joint Surg Br. 1997;79:644-647.

14. Easley ME, Trnka HJ, Schon LC, Myerson MS. Isolated subtalar arthrodesis. J Bone Joint Surg Am. 2000;82:613-624.

15. Ebalard M, Le Henaff G, Sigonney G, Lopes R, Kerhousse G, Brilhault J, Huten D. Risk of osteoarthritis secondary to partial or total arthrodesis of the subtalar and midtarsal joints after a minimum follow-up of 10 years. Orthop Traumatol Surg Res. 2014;100(4 suppl):S231-237.

16. Imhauser CW, Siegler S, Udupa JK, Toy JR. Subject-specific models of the hindfoot reveal a relationship between morphology and passive mechanical properties. J Biomech. 2008;41:1341-1349.

17. Jastifer JR, Gustafson PA, Gorman RR. Subtalar arthrodesis alignment: the effect on ankle biomechanics. Foot Ankle Int. 2013;34:244-250. 
18. Joveniaux P, Harisboure A, Ohl X, Dehoux E. Long-term results of in situ subtalar arthrodesis. Int Orthop. 2010;34:1199-1205.

19. Kim BS, Knupp M, Zwicky L, Lee JW, Hintermann B. Total ankle replacement in association with hindfoot fusion: outcome and complications. J Bone Joint Surg Br. 2010;92:1540-1547.

20. Kim PH, Chen X, Hillstrom H, Ellis SJ, Baxter JR, Deland JT. Moberg osteotomy shifts contact pressure plantarly in the first metatarsophalangeal joint in a biomechanical model. Foot Ankle Int. 2015 Sept 18. [Epub ahead of print]

21. Ko FC, Dragomir C, Plumb DA, Goldring SR, Wright TM, Goldring MB, van der Meulen MC. In vivo cyclic compression causes cartilage degeneration and subchondral bone changes in mouse tibiae. Arthritis Rheum. 2013;65:1569-1578.

22. Leardini A, Stagni R, O'Connor JJ. Mobility of the subtalar joint in the intact ankle complex. J Biomech. 2001;34:805-809.

23. Loeser RF, Goldring SR, Scanzello CR, Goldring MB. Osteoarthritis: a disease of the joint as an organ. Arthritis Rheum. 2012;64:1697-1707.

24. Mann RA, Beaman DN, Horton GA. Isolated subtalar arthrodesis. Foot Ankle Int. 1998;19:511-519.

25. Milentijevic D, Torzilli PA. Influence of stress rate on water loss, matrix deformation and chondrocyte viability in impacted articular cartilage. J Biomech. 2005;38:493-502.

26. Oh I, Imhauser C, Choi D, Williams B, Ellis S, Deland J. Sensitivity of plantar pressure and talonavicular alignment to lateral column lengthening in flatfoot reconstruction. J Bone Joint Surg Am. 2013;95:1094-1100.

27. Payette CR, Sage RA, Gonzalez JV, Sartori M, Patwardhan A, Vrbos L. Triple arthrodesis stabilization: a quantitative analysis of screw versus staple fixation in fresh cadaveric matched-pair specimens. J Foot Ankle Surg. 1998;37:472-480.

28. Pell RF 4th, Myerson MS, Schon LC. Clinical outcome after primary triple arthrodesis. J Bone Joint Surg Am. 2000;82:47-57.

29. Sammarco VJ, Magur EG, Sammarco GJ, Bagwe MR. Arthrodesis of the subtalar and talonavicular joints for correction of symptomatic hindfoot malalignment. Foot Ankle Int. 2006;27:661-666.

30. Siegler S, Toy J, Seale D, Pedowitz D. The Clinical Biomechanics Award 2013-presented by the International Society of Biomechanics: new observations on the morphology of the talar dome and its relationship to ankle kinematics. Clin Biomech (Bristol, Avon). 2014;29:1-6.
31. Smith RW, Shen W, Dewitt S, Reischl SF. Triple arthrodesis in adults with non-paralytic disease; a minimum ten-year follow-up study. J Bone Joint Surg Am. 2004;86:2707-2713.

32. Stormont DM, Morrey BF, An KN, Cass JR. Stability of the loaded ankle: relation between articular restraint and primary and secondary static restraints. Am J Sports Med. 1985;13:295-300.

33. Suckel A, Muller O, Herberts T, Langenstein P, Reize P, Wulker N. Talonavicular arthrodesis or triple arthrodesis: peak pressure in the adjacent joints measured in 8 cadaver specimens. Acta Orthop. 2007;78:592-597.

34. Suckel A, Muller O, Herberts T, Langenstein P, Wulker N. [Loading of the tibiotalar joint and Chopart's joint following subtalar arthrodesis: dynamic cadaver study of 5 specimens][in German]. Z Orthop Unfall. 2008;146:86-91.

35. Tochigi Y, Rudert MJ, Saltzman CL, Amendola A, Brown TD. Contribution of articular surface geometry to ankle stabilization. J Bone Joint Surgery Am. 2006;88:2704-2713.

36. Tuijthof GJ, Zengerink M, Beimers L, Jonges R, Maas M, van Dijk CN, Blankevoort L. Determination of consistent patterns of range of motion in the ankle joint with a computed tomography stress-test. Clin Biomech (Bristol, Avon). 2009;24:517-523.

37. Wang H, Chen T, Koff MF, Hutchinson ID, Gilbert S, Choi D, Warren RF, Rodeo SA, Maher SA. Image based weighted center of proximity versus directly measured knee contact location during simulated gait. J Biomech. 2014;47:2483-2489.

38. Wang $\mathrm{H}$, Chen $\mathrm{T}$, Torzilli $\mathrm{P}$, Warren R, Maher S. Dynamic contact stress patterns on the tibial plateaus during simulated gait: a novel application of normalized cross correlation. J Biomech. 2014;47:568-574.

39. Wang H, Gee AO, Hutchinson ID, Stoner K, Warren RF, Chen TO, Maher SA. Bone plug versus suture-only fixation of meniscal grafts: effect on joint contact mechanics during simulated gait. Am J Sports Med. 2014;42:1682-1689.

40. Wu G, Siegler S, Allard P, Kirtley C, Leardini A, Rosenbaum D, Whittle M, D'Lima DD, Cristofolini L, Witte H, Schmid O, Stokes I, Standardization and Terminology Committee of the International Society of Biomechanics. ISB recommendation on definitions of joint coordinate system of various joints for the reporting of human joint motion: Part I: ankle, hip, and spine. International Society of Biomechanics. J Biomech. 2002;35:543548. 